\title{
PHYSICIAN-PATIENT COMMUNICATION AMONG SOUTHERN EUROPEAN CANCER PHYSICIANS: THE INFLUENCE OF PSYCHOSOCIAL ORIENTATION AND BURNOUT
}

\author{
LUZIA TRAVADO ${ }^{\mathrm{a}, \mathrm{b}, *}$, LUIGI GRASSI $^{\mathrm{c}, \mathrm{d}}$, FRANCISCO GIL $^{\mathrm{e}}$, CIDÁLIA VENTURA $^{\mathrm{a}}$, CRISTINA MARTINS $^{\mathrm{a}}$ AND THE \\ SOUTHERN EUROPEAN PSYCHO-ONCOLOGY STUDY (SEPOS) GROUP ${ }^{\dagger}$

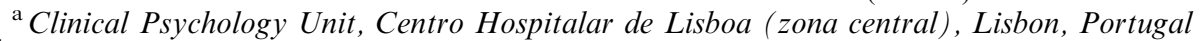 \\ ${ }^{\mathrm{b}}$ Faculty of Psychology and Educational Sciences, Independent University, Lisbon, Portugal \\ ${ }^{\mathrm{c}}$ Department of Behavior and Communication, Section of Psychiatry, University of Ferrara, Italy \\ ${ }^{\mathrm{d}}$ Department of Mental Health and General University, S. Anna Hospital, Ferrara, Italy

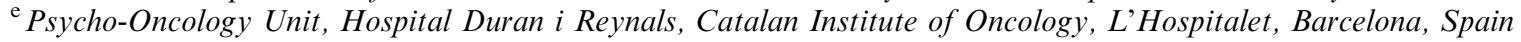

\begin{abstract}
SUMMARY
Physician-patient communication is a critical factor for comprehensive care in oncology. Although a number of studies have been carried out in Northern Europe and the US on this subject, no data are available in Southern European countries. As a part of a multicenter Southern European Psycho-Oncology study (SEPOS), the present investigation was conducted to examine communication skills and related variables (i.e. psychosocial orientation, and burnout) among 125 physicians from Italy, Portugal, and Spain. The Self-Confidence in Communication Skills (SCCS) scale was given to assess physicians' perception of their communication skills and the Expected Outcome of Communication (EOC) scale was administered to examine the physicians' expectations about the effects of communicating with their patients. Doctors' psychosocial orientation was measured by using the Physician Belief Scale (PBS) and burnout was measured by using the Maslach Burnout Inventory (MBI). Although the physicians reported receiving minimal training in communication during their education, they tended to perceive themselves as skilled in patient communication, apart from some areas (e.g. dealing with denial, managing uncertainty, assessing anxiety and depression, and promoting patient-family openness). Low psychosocial orientation and burnout symptoms (i.e. emotional exhaustion, depersonalization, and poor personal accomplishment in their job) were associated with lower confidence in communication skills and higher expectations of a negative outcome, following physician-patient communication. The results suggest that there is a need for training cancer physicians in communication and for increasing a more definite psychosocially oriented approach in cancer care in Mediterranean countries. Copyright (C) 2005 John Wiley \& Sons, Ltd.
\end{abstract}

\section{INTRODUCTION}

\begin{abstract}
*Correspondence to: Unidade de Psicologia Clínica, Centro Hospitalar de Lisboa (zona central), Hospital de S. José (piso intermédio) Rua José António Serrano, 1150-199 Lisboa, Portugal. E-mail: luzia.travado@hsjose.min-saude.pt

† The SEPOS Group that worked at the project 'Improving health staff's communication and assessment skills of psychosocial morbidity and quality of life in cancer patients: a study in Southern European countries' (Principal Investigator Luigi Grassi, MD), was formed by the following persons: Sónia Cunha $^{\text {a }}$; Rute Pires ${ }^{\mathrm{a}}$; Hugo Lucas ${ }^{\mathrm{a}}$; Katia Magnani, ${ }^{\mathrm{c}, \mathrm{d}}$; Silvana Sabato $^{\mathrm{c}, \mathrm{d}}$; Elena Rossi ${ }^{\mathrm{c}, \mathrm{d}}$; Giulia Trallic, ${ }^{\mathrm{c}, \mathrm{d}}$ Purificación Lluch Maria Francisca Hollenstein ${ }^{e}$; Jorge Maté ${ }^{e}$.
\end{abstract}

The importance of communication has been repeatedly underscored in oncology as the cornerstone of physician-patient relationship (Arora, 2003; Fallowfield and Jenkins, 1999, 2004; Maguire, 1999; Maguire and Pitceathly, 2002; Razavi and Delvaux, 1997). A number of studies have been carried out about this important area by examining the way in which cancer physicians communicate with their patients (e.g. use of open questions, active listening, clarification, screening for problem areas, encouraging patients to express 
concerns and emotions, empathic response). It has been shown that physician's ability in communicating and relating with their patients facilitates the early detection of emotional problems and early referral, with prevention of possible psychological complications (Parle et al., 1996, 1997). Good patient-centered communication has been also reported as having positive outcomes on various patient health measures, such as compliance with medical treatments, symptom resolution, pain control (Stewart, 1984, 1996), and adjustment to illness (Mager and Andrykowski, 2002; Roberts et al., 1994). Furthermore, although cancer patient's satisfaction is influenced by several variables (e.g. length of wait in clinic) (Shilling et al., 2003), it is also positively increased by physicians' communication skills (Kinnersley et al., 1999).

For these reasons, specific training programs in communication skills for oncology health professionals, particularly physicians, have been recommended to be part of routine education in cancer settings. Several programs have been developed with the aims of training doctors in interviewing techniques, in providing patients with the opportunity to express feelings and emotions, in eliciting patients' concerns and problems, and in assessing possible symptoms of psychosocial distress (Back et al., 2003; Baile et al., 1999; Fallowfield et al., 1998, 2003; Maguire et al., 1996; Parle et al., 1997; Razavi et al., 2000, 2003). It is widely acknowledged that learning communication skills and applying them in routine clinical practice with cancer patients requires a significant shift from a traditional biomedical paternalistic perspective to a more patient-centered biopsychosocial approach. In this approach, patients are viewed as whole persons and their psychological and social dimensions along with the biological one are valued and taken into consideration in their health care, including patients' perspective and participation in decision-making (Reis, 1998). While in the biomedical model the focus is biological and patients are expected to comply with prescriptions having a quite passive role. There is evidence that physicians' beliefs toward psychosocial aspects of health care influence their attitudes regarding the use of more skilled and useful communication techniques. In a study of primary care physicians, Levinson and Roter (1995) observed that physicians who were more psychosocially oriented tended to be more empathic in their consultations, provided more psychosocial information, and were more open and actively involved in answering their patient's questions. Jenkins and Fallowfield (2002) showed that communication skills were associated with physician's attitudes towards psychosocial issues. In their study, the authors demonstrated that physicians who completed a specific 3-day intensive training course on communication skills that also fostered a psychosocial orientation, significantly improved and maintained the use of these skills in their practice in comparison with those who completed a shorter training.

Along with psychosocial orientation, a further variable which may influence communication skills is physicians' burnout symptoms, such as high emotional stress and exhaustion, detachment in dealing with patients and poor satisfaction with their work. Poor or insufficient training in communication skills has been found to contribute to physician burnout (Ramirez et al., 1995, 1996), while training in communication can both improve physician confidence and decrease the level of burnout (Armstrong and Holland, 2004; Baile et al., 1997).

In Southern European countries, the area of physician-patient communication has been examined in terms of physicians' attitudes toward truthtelling with cancer patients (Arraras et al., 1995; Ferraz Gonçalves and Castro, 2001; Gil et al., 2000; Grassi et al., 2000), patients' awareness of their disease (Morasso et al., 1997; Mystadikou et al., 1996) and patients' desire for information during communication with their doctors (De Lorenzo et al., 2004; Pimentel et al., 1999). In contrast, no study in these countries has assessed the area of cancer physicians' communications skills, physicians' psychosocial orientation and the relationship between these two variables. Also, no data are available regarding the association between communication skills and burnout.

Recently, a research project involving countries in the Mediterranean area (Southern European Psycho-Oncology Study-SEPOS) was developed to examine psychosocial problems secondary to cancer, to rate the extent to which such problems are recognized by oncologists, and to develop and implement a training model designed to improve physicians' ability to recognize and detect psychological disorders (Grassi et al., 2004, in press). As a part of the aforementioned larger investigation, the objectives of the present study were (i) to characterize in more detail cancer physicians' communication skills in terms of their own confidence in specific skills and their expectations of outcome of communication with patients; 
(ii) to examine the relationship of these variables with psychosocial orientation and burnout.

\section{METHODS}

\section{Subjects}

A convenience sample of 125 physicians was recruited in cancer centers of the three hospitals participating in the project in Italy (S. Anna University Hospital, Ferrara), Portugal (Hospital S. José, Lisbon) and Spain (Catalan Institute of Oncology, Barcelona). The first two are general hospitals with cancer wards, while the third is a cancer hospital. In all the three sites a psychooncology service is active for many years.

\section{Procedure}

Physicians working in the three hospital centers where the entire research project was carried out were recruited through an advertisement about the aims of the study. All the doctors were invited to a meeting in which detailed information on the SEPO study was given. The general aims of the research were presented, as reported elsewhere (Grassi et al., 2004), including the aspect relative to the assessment of physicians' characteristics in terms of communications skills, psychosocial orientation, and burnout symptoms. The same methodology was followed in the three hospital centers. After giving their consent to participate, each physician was individually administered a series of questionnaires by a research fellow.

\section{Measures}

Communication skills was assessed by using two scales, the Self-Confidence in Communications Skills (SCSS) and the Expected Outcomes of Communication (EOC) (Maguire, 1996; Parle et al., 1997). Physicians' psychosocial orientation was evaluated by using the Physician Belief Scale (PBS) (Ashworth et al., 1984), and burnout was assessed by using the Maslach Burnout Inventory (MBI) (Maslach and Jackson, 1986). The SCSS is a 12 -item instrument investigating, on a $0-100$ scale, the confidence of physicians in rating their ability to communicate with patients and successfully manage a series of clinical situations (e.g. 'initiate a discussion with a patient about their illness and concerns', 'assess a patient knowledge and understanding about their disease', 'break bad news', 'help a patient manage uncertainty'). A single question regarding the amount of the training (in hours) the physicians had received in communications skills was also included. According to Maguire (1996), four categories were indicated: $\leqslant 24,25-50,50-100,>100 \mathrm{~h}$.

The EOC is a 23-item assessing the extent to which physicians think the result of their communication with patients will be positive or negative. Physicians were asked to rate on a 9-point Likert scale (from $1=$ 'very likely' to $9=$ 'very unlikely'), how likely they considered a series of possible outcomes which could result as a consequence of their communication with patients (e.g. 'asking your patient to talk about their illness and concerns will damage the way they cope'; 'you will get too close to your patient if you ask about their feelings and concerns'; 'asking patients about their concerns and feelings will be useful for you in your management of the patient'). Both the SCSS and the EOC showed to be reliable in previous studies on doctors' communication skills (Maguire, 1996; Parle et al., 1997).

The PBS consists of 32 items that assess physicians' beliefs about the psychosocial dimensions of patient care. Physicians are asked to rate on a 5-point Likert scale (from 1='strongly disagree' to $5=$ 'strongly agree') the degree of agreement with a series of beliefs regarding their role as physicians (e.g. 'I cannot treat psychosocial problems'), their own reactions to their patients (e.g. 'Exploring psychosocial issues with the patient often causes me pain'), and their perception of the patients' attitudes towards psychosocial issues (e.g. 'My patients do not want me to investigate psychosocial problems'). According to original version of the scale, a PBS total score was obtained by summing up the response to the 32 items (range 32-160) with lower scores corresponding to high psychosocial orientation. The scale proved to be a reliable and valid measure of psychosocial orientation of physicians both in the original version (Ashworth et al., 1984) and in a modified version (e.g. items reversed with higher score corresponding to higher psychosocial orientation) (Jenkins and Fallowfield, 2002).

The MBI is a 22-item measure of burnout in health care professions through three subscales: Emotional Exhaustion (nine items), evaluating feelings of overwhelming and exhaustion by one's 
own work; Depersonalization (five items), measuring detachment and feelings of impersonal response towards the patients; Personal Accomplishment (eight items), assessing feelings of competence and achievement in one's own work. The recommended cut-off scores (i.e. no/low burnout, intermediate, and high burnout) (Maslach and Jackson, 1986) were employed for all the three subscales. The MBI has been used in several studies and proved to be reliable in measuring burnout among physicians (Catalan et al., 1996; Grassi and Magnani 2000; Grunfeld et al., 2002; Ramirez et al., 1995).

\section{Statistical analysis}

The data from this study were analyzed in several steps. First, mean scores, standard deviations (SDs), and Cronbach's alphas were obtained for each measure. All data were verified for normal distribution and kurtosis. Frequencies and descriptives were obtained for all measures. Second, Spearman's $r$ coefficient test was conducted to examine intercorrelations among the variables. Third, because of non-normality of the data, a non-parametric test, the Kruskal-Wallis, was used to test for differences between countries on median scores of variables. Last, a principal components analysis for categorical data was performed on EOC scale to identify its characteristics. The level of statistical significance was set at $1 \%$.

\section{RESULTS}

\section{Demographic characteristics of the physicians}

Demographic characteristics of the sample are presented in Table 1. There were $46.4 \%$ males $(n=58)$ and $53.6 \%$ females $(n=67)$, with a mean age of 41.81 (SD 9.72). Mean years of practice were 14.98 (SD 9.43). Of the 125 physicians that participated in the study, $44(35.2 \%)$ were from Italy, $41(32.8 \%)$ from Portugal and 40 $(32 \%)$ from Spain. Italian physicians were the oldest $(46.26 \pm 9.84)$ and had more years of practice $(18.1 \pm 10.7)$, while Spanish were the youngest $(37.6 \pm 8.3)$ and had less years of practice $(10.9 \pm$ 7.2) $(F=9.57, \quad p<0.01$, and $F=6.5, \quad p<0.01$, respectively) (Table 1).

\section{Communication skills and expected outcomes}

The SCCS showed a high level of internal consistency (Cronbach $\alpha=0.95$ ). In order to describe the doctors' perception of their skill in the single area, the mean scores (and SD) for each item, together with the overall mean score were computed (Table 2). Physicians reported high levels of confidence in communication skills such as eliciting patient's worries $(82.8 \pm 15.3)$, summarizing $(78.9 \pm 16.4)$, evaluating patient's awareness $(77.1 \pm 16.6)$, dealing with own emotions $(75.6 \pm 19.1)$, favoring patient's openness $(74.9 \pm$ 17.7), favoring the process of communication $(74.2 \pm 17.4)$, helping patient to show his/her concerns $(74.2 \pm 18.7)$. Lower levels of confidence were found in more complex skills such as, giving bad news $(72.36 \pm 21.6)$, evaluating anxiety and depression $(69.9 \pm 16.8)$, promoting family communication $(69.3 \pm 19.2)$, helping with uncertainty $(67.5 \pm 21.2)$ and dealing with denial $(64.1 \pm$ 20.7). Portuguese physicians reported higher overall confidence levels $(82.9 \pm 14.3)$ than Italian $(68.8 \pm 13.7)$ and Spanish $(69.6 \pm 12.8)$ physicians $(F=13.99, p<0.01)$. These differences were maintained when the single skills were examined

Table 1. Demographic characteristics of the physicians

\begin{tabular}{llllll}
\hline & $\begin{array}{l}\text { Total sample } \\
(n=125)\end{array}$ & $\begin{array}{l}\text { Italy } \\
(n=44)\end{array}$ & $\begin{array}{l}\text { Portugal } \\
(n=41)\end{array}$ & $\begin{array}{l}\text { Spain } \\
(n=40)\end{array}$ & $p$ \\
\hline $\begin{array}{l}\text { Sex } \\
\quad \text { Male }\end{array}$ & $\begin{array}{l}58(46.4 \%) \\
\text { Female }\end{array}$ & $\begin{array}{l}24(54.5 \%) \\
20(45.5 \%)\end{array}$ & $\begin{array}{l}18(43.9 \%) \\
23(56.1 \%)\end{array}$ & $\begin{array}{l}16(40 \%) \\
24(60 \%)\end{array}$ & $\chi^{2}=1.93$ \\
$\begin{array}{l}\text { Age (yrs) } \\
(25-70)\end{array}$ & $41.81 \pm 9.72$ & $46.26 \pm 9.84$ & $41.22 \pm 9.00$ & $37.58 \pm 8.28$ & $F=9.57$ \\
$\begin{array}{l}\text { Years of practice } \\
(1-43)\end{array}$ & $14.98 \pm 9.43$ & $18.10 \pm 10.77$ & $15.63 \pm 8.62$ & $10.95 \pm 7.20$ & $F=6.50$ \\
\hline
\end{tabular}


Table 2. Mean scores (and S.D.s) on the Self-Confidence in Communications Skills on the single items and the total score for the total sample and each country

\begin{tabular}{|c|c|c|c|c|c|c|}
\hline & Total & Italy & Portugal & Spain & $F$ & $p$ \\
\hline 1. Eliciting patient's worries & $82.86(15.27)$ & $81.93(13.94)$ & $87.51(15.13)$ & $79.13(15.93)$ & 3.30 & 0.040 \\
\hline 2. Evaluating patient's awareness & $77.16(16.61)$ & $72.16(18.50)$ & $84.63(15.31)$ & $75.00(12.96)$ & 7.12 & 0.001 \\
\hline 3. Favoring patient's openness & $74.91(17.75)$ & $72.27(15.42)$ & $84.49(16.40)$ & $68.00(17.61)$ & 11.02 & 0.000 \\
\hline 4. Helping patient to show his/her concerns & $74.19(18.76)$ & $67.61(17.70)$ & $84.85(15.85)$ & $70.50(18.25)$ & 11.88 & 0.000 \\
\hline 5. Summarizing & $78.91(16.39)$ & $71.48(17.90)$ & $87.66(14.01)$ & $78.13(12.39)$ & 12.32 & 0.000 \\
\hline 6. Favoring the process & $74.20(17.40)$ & $64.32(16.62)$ & $84.27(16.75)$ & $74.75(12.35)$ & 17.77 & 0.000 \\
\hline 7. Giving bad news & $72.36(21.62)$ & $64.09(23.29)$ & $84.27(16.57)$ & $69.25(19.27)$ & 11.52 & 0.000 \\
\hline 8. Evaluating anxiety and depression & $69.90(16.82)$ & $69.48(17.66)$ & $76.10(16.26)$ & $64.00(14.42)$ & 5.65 & 0.004 \\
\hline 9. Helping with uncertainty & $67.52(21.25)$ & $63.52(20.67)$ & $78.78(17.99)$ & $60.38(20.71)$ & 10.01 & 0.000 \\
\hline 10. Dealing with denial & $64.06(20.78)$ & $56.59(19.40)$ & $76.66(20.24)$ & $59.38(16.88)$ & 13.74 & 0.000 \\
\hline 11. Promoting family communication & $69.35(19.25)$ & $64.43(18.53)$ & $80.71(18.26)$ & $63.13(15.96)$ & 12.67 & 0.000 \\
\hline 12. Dealing with own emotions & $75.60(19.10)$ & $69.89(20.07)$ & $80.20(18.48)$ & $75.13(16.66)$ & 4.71 & 0.011 \\
\hline Total score & $73.76(15.00)$ & $68.84(13.68)$ & $82.98(14.31)$ & $69.73(12.86)$ & 13.99 & 0.000 \\
\hline
\end{tabular}

separately (Table 2). Data about hours of training in communication skills were available from only 95 physicians $(76 \%)$. A large majority of them $(n=82 ; 86.3 \%)$ reported receiving minimal or no training in communication skills $(\leqslant 24 \mathrm{~h})$, while only a few $(n=13 ; 13.7 \%)$ reported receiving training from specific courses $(25-50 \mathrm{~h}$ : $n=8,8.4 \% ; 50-100 \mathrm{~h}: n=5,5.3 \%)$. No significant differences across countries were found on hours of training in communication skills.

As regarding the EOC, a principal components analysis for categorical data was performed in order to have a clearer description of the doctors' expected outcomes of their communication. Two components emerged. A first component, designated EOC negative, consisted of 15 items reflecting negative expectations regarding the outcome of communication (factor loadings ranging from 0.32 to 0.74 explaining $60.47 \%$ of the variance). A second component, designated EOC positive, consisted of eight items asserting beneficial outcomes of communication (factor loadings ranging from 0.31 to 0.75 explaining $31.15 \%$ of the variance). Both components showed acceptable levels of reliability (Cronbach $\alpha=0.87$ for EOC negative and 0.71 for EOC positive). The mean score for the EOC positive in the sample was $3.41 \pm 1.17$ while the mean score for the EOC negative was $5.85 \pm 1$, with Portuguese and Italian physicians expressing more likelihood upon positive outcomes of communication than Spanish physicians $(F=8.14, p<0.01)$ (Table 3).

\section{Psychosocial orientation and burnout}

The PBS showed acceptable levels of reliability (Cronbach $\alpha=0.78$ ). The mean total score of the instrument was $85.65 \pm 10.89$, with small differences between countries (Portuguese physicians being the most psychosocially oriented and Spanish physicians the least) (Table 3).

The MBI showed acceptable levels of reliability in Emotional Exhaustion (Cronbach $\alpha=0.89$ ), Depersonalization (Cronbach $\alpha=0.67$ ), and Personal Accomplishment (Cronbach $\alpha=0.76$ ) subscales. Among 121 physicians who completed the questionnaire, $31(25.6 \%)$ reported high scores on the Emotional Exhaustion subscale, 27 (22.3\%) on Depersonalization and $26(21.4 \%)$ showed scores indicating poor personal accomplishment. In comparison with Italian and Portuguese physicians, Spanish doctors had the highest levels of MBI-Depersonalization $(F=13.07, p<0.001)$ and the lowest levels of MBI-Personal Accomplishment $(F=7.22, p<0.01) \quad$ (Table 4$)$. This was confirmed by analyzing the percentages of physicians fitting into the categories of burnout according to the three MBI scales (Depersonalization $\chi^{2}=18.4, \mathrm{df}=4, p=0.001$; Personal Accomplishment $\left.\chi^{2}=11.89, \mathrm{df}=4, p=0.018\right)$.

\section{Correlations between the measures}

The correlations between the measures are reported in Table 5. Neither age nor years of 
Table 3. Mean total scores (and SDs) on the Expected Outcome of Communication positive and negative subscales and the PBS for the total sample and the three countries

\begin{tabular}{lllllll}
\hline & Total & Italy & Portugal & Spain & $F$ & $p$ \\
\hline Negative EOC & $5.85 \pm 1.00$ & $5.72 \pm 1.06$ & $6.11 \pm 1.04$ & $5.72 \pm 0.84$ & 2.15 & 0.12 \\
Positive EOC & $3.41 \pm 1.17$ & $3.09 \pm 1.10$ & $3.18 \pm 1.1$ & $3.99 \pm 1.12$ & 8.14 & 0.001 \\
PBS* & $85.65+10.89$ & $85.51+13.76$ & $82.27+8.69$ & $89.36+8.09$ & 4.48 & 0.013 \\
\hline
\end{tabular}

*Data available for 123 physicians (Italy $=43$, Portugal $=41$, Spain $=39$ ).

Table 4. Mean scores (and SDs) on the Maslach Burnout Inventory for the total sample and each country and percentage of burnout level for each subscale

\begin{tabular}{|c|c|c|c|c|c|c|}
\hline Burnout subscales & $\begin{array}{l}\text { Total } \\
(n=121)\end{array}$ & $\begin{array}{l}\text { Italy } \\
(n=44)\end{array}$ & $\begin{array}{l}\text { Portugal } \\
(n=38)\end{array}$ & $\begin{array}{l}\text { Spain } \\
(n=39)\end{array}$ & & \\
\hline Emotional exhaustion & $20.21 \pm 11.04$ & $18.75 \pm 12.12$ & $19.79 \pm 10.91$ & $22.28 \pm 9.79$ & $F=1.101$ & $p=0.336$ \\
\hline - No/low $(\leqslant 18)$ & $60(49.6 \%)$ & $23(52.2 \%)$ & $22(57.9 \%)$ & $15(38.5 \%)$ & $\chi 2=5.62$ & $p=\mathrm{NS}$ \\
\hline - Intermediate (19-26) & $30(24.8 \%)$ & $12(27.2 \%)$ & $5(13.2 \%)$ & $13(33.3 \%)$ & & \\
\hline - High $(\geqslant 27)$ & $31(25.6 \%)$ & $9(20.4 \%)$ & $11(28.9 \%)$ & $11(28.2 \%)$ & & \\
\hline Depersonalization & $5.89 \pm 4.90$ & $4.32 \pm 4.16$ & $4.63 \pm 4.10$ & $8.9 \pm 5.09$ & $F=13.074$ & $p=0.001$ \\
\hline - No/low $(\leqslant 5)$ & $68(56.1 \%)$ & $31(70.4 \%)$ & $24(63.2 \%)$ & $13(33.3 \%)$ & $\chi^{2}=18.4$ & $p=0.001$ \\
\hline . Intermediate (6-9) & $26(21.4 \%)$ & $7(15.9 \%)$ & $10(26.3 \%)$ & $9(23.1 \%)$ & & \\
\hline - High $(\geqslant 10)$ & $27(22.3 \%)$ & $6(13.6 \%)$ & $4(10.5 \%)$ & $17(43.6 \%)$ & & \\
\hline Personal accomplishment & $37.84 \pm 5.55$ & $38.89 \pm 6.91$ & $39.79 \pm 5.24$ & $34.77 \pm 6.31$ & $F=7.22$ & $p=0.001$ \\
\hline - No/low $(\geqslant 40)$ & $49(40.4 \%)$ & $22(50.0 \%)$ & $19(50.0 \%)$ & $8(20.5 \%)$ & $\chi^{2}=11.89$ & $p=0.018$ \\
\hline - Intermediate (34-39) & $46(38.0 \%)$ & $13(29.5 \%)$ & $15(39.5 \%)$ & $18(46.2 \%)$ & & \\
\hline - High $(\leqslant 33)$ & $26(21.4 \%)$ & $9(20.5 \%)$ & $4(10.5 \%)$ & $13(33.3 \%)$ & & \\
\hline
\end{tabular}

Table 5. Correlation between the measures

\begin{tabular}{lllllll}
\hline & $\begin{array}{l}\text { EOC } \\
\text { negative }\end{array}$ & $\begin{array}{l}\text { EOC } \\
\text { positive }\end{array}$ & PBS & MBI-exhaustion & MBI-depersonalization & MBI-accomplishment \\
\hline SCSS & $0.49^{* *}$ & $-0.24^{* *}$ & $-0.19^{*}$ & -0.03 & -0.08 & $0.37^{* *}$ \\
Negative EOC & & -0.06 & $-0.43^{* *}$ & $-0.21^{*}$ & $-0.25^{* *}$ & $0.28^{* *}$ \\
Positive EOC & & & $0.19^{*}$ & 0.01 & $0.34^{* *}$ & $-0.28^{* *}$ \\
PBS & & & $0.26^{* *}$ & $0.45^{* *}$ & -0.14 \\
MBI-exhaustion & & & & $0.48^{* *}$ & $-0.33^{* *}$ \\
MBI-depersonalization & & & & & $-0.37^{* *}$ \\
\hline
\end{tabular}

${ }^{*} p<0.05,{ }^{* *} p<0.01$.

practice were related to the psychological measures. Significant correlations were found between the SCCS total score and both the EOC positive $(r=-0.24, \quad p<0,01)$ and EOC negative scores $(r=0.49, p<0.01)$ (the greater physicians' self-confidence in their ability to communicate effectively, the more positive expectancies, and fewer negative expectancies they had).
The PBS was also significantly correlated with the EOC negative $(r=-0.43, p<0.01)$, MBI-Emotional Exhaustion $(r=0.26, \quad p<0.01)$ and MBI-Depersonalization $(r=0.45, p<0.01)$ (the higher psychosocial orientation, the less negative expectations of the outcome of communication with patients and less Emotional Exhaustion and Depersonalization). 
With regard to the MBI, Emotional Exhaustion was moderately correlated with the EOC negative score $(r=-0.21, p=0.02)$ (the higher Emotional Exhaustion, the more negative expectations). Depersonalization was associated both with EOC negative $(r=-0.25, p<0.01)$, and EOC positive $(r=0.34, p<0.01)$, in which higher depersonalization correlates with more negative and less positive expectations. Personal Accomplishment was significantly and positively correlated with the SCCS total score $(r=0.37, p<0.01)$, EOC negative $(r=0.28, p<0.01)$, and EOC positive $(r=-0.28$, $p<0.01$ ), in which the greater physicians' sense of personal accomplishment, the higher self-confidence in their ability to communicate effectively and the more positive expectancies and fewer negative expectancies they had.

\section{DISCUSSION}

The present study examined the main characteristics of communication skills and its relation with psychological variables (i.e. psychosocial orientation, and burnout) among cancer physicians' in Southern European countries, namely Italy, Portugal and Spain. Although most physicians reported to have received no or minimum training in communication during their education, they described themselves as quite confident in several skills, such as eliciting patient's worries, favoring their patient's openness, breaking bad news, and summarizing. However, they described themselves as less confident in other areas of communication, such as evaluating anxiety and depression, helping with uncertainty, dealing with denial and promoting family communication. These figures are different from those reported by Parle et al. (1997) who, using the same instrument, found that physicians showed less confidence in most communication skills. A cultural artifact might explain this difference, since a paternalistic view of medicine, which is still predominant in Southern European countries, could induce physicians to consider themselves competent in skills that are not completely performed. A second possibility could be related to the different population examined in this study with respect to other studies. Parle et al.'s study (1997), for example, evaluated physicians who had been recruited for participation in communication skills workshops and were much more aware of their problems in this area than the physicians in our study. Since a high level of confidence in communication skills does not certify or grant adequate communication behavior, further investigation is necessary concerning this subject.

Confidence in their own communication skills was not related to age or years of practice, while it was related to the expected outcome of communication, with more confident physicians reporting more positive expectations and less confident physicians reporting more negative expectations. However, it is possible that physicians tended to report adequate expectations when the outcome was presented as positive (e.g. 'asking them to talk about their concerns and emotions will benefit them'), whereas they tended to have difficulty in rejecting the outcome when it was presented as negative (e.g. 'Your patient will become uncontrollably upset if you ask about their feelings', 'Talking about fears and worries will distress your patient and make them cry'). This pattern of expectations might indicate barriers and fears in communicating with patients, with regard to both the patients (e.g. fear of producing patient's emotional and behavioral distress, fear of being unprofessional or assuming too much responsibility) and the physicians (e.g. anticipation of negative consequences at personal/emotional level, negative professional impact, not their role or area of competence, and lack of support). Interesting results emerged also from the analysis of the physicians' psychosocial orientation. In fact, scores on the PBS indicated that physicians were not convinced about the importance of the psychosocial aspects in health care or they were still attached to traditional biomedical values. More specifically, physicians were uncertain about their patients' psychosocial needs and about their own reactions to the patients if they discussed psychosocial issues, wondering if they would approve of their questioning. These figures appear to be different from those reported by Ashworth et al. (1984) who found a slightly higher psychosocial orientation in other medical professions (i.e. psychiatry, internal medicine, and family medicine), but quite similar to what reported by Jenkins and Fallowfield (2002) among oncologists. This may indicate specific difficulties that cancer physicians have, especially in Southern Europe, in maintaining an appropriate psychosocial vision of their patients. A lower level of psychosocial orientation was associated with lower confidence in communication skills (SCCS score), higher 
expectations that their communication with patients can have negative effects (e.g. devastating the patient, being too much involved in the relationship) and, to a lesser degree, with lower expectations of obtaining positive outcomes (e.g. benefit the patient, having support from colleagues). These results support the view that low psychosocial orientation of physicians negatively influences their communication skills with cancer patients (Jenkins and Fallowfield, 2002). Interestingly, physicians with low psychosocial orientation also had high levels of burnout, namely emotional exhaustion (feeling emotionally overwhelmed by their work) and depersonalization (high levels of indifference and distancing attitudes towards their patients). A significant association was also found between burnout and communication skills. In fact, physicians who scored high in depersonalization tended to consider it very unlikely that a positive outcome would be achieved as a result of communicating with their patients (e.g. asking them to talk about their concerns and emotions will benefit them), whereas they considered it more likely a negative outcome (e.g. the patient will become uncontrollably upset if asked about his/her feelings). Opposite results were found among physicians who perceived themselves as fulfilled and gratified by their work (personal accomplishment), who had higher scores on the positive EOC, lower scores on the negative EOC, as well as higher scores in communication skills in general (SCCS total score). These results suggest an important influence of physicians' psychosocial orientation and burnout on their characteristics of communication with patients.

Some differences were found when analyzing physicians' responses across countries. Portuguese physicians described themselves as more confident in communicating with their patients and in expecting less negative outcome from communication in comparison with Italian and Spanish physicians. They also were more psychosocially oriented (PBS) than Spanish physicians. As far as burnout is concerned, Spanish physicians reported that they were more emotionally exhausted, more detached and less accomplished in their work than Italian and Portuguese physicians, yet with prevalence of burnout comparable to previous research carried out among Italian and Spanish general practitioners (Grassi and Magnani, 2000; Molina Siguero et al., 2003). Because of the small sample of participants, the different contexts where the study was carried out (two general hospitals and one cancer hospital) and the different systems in health organization between the countries, caution is needed in evaluating these results. More research is necessary in order to investigate about this specific area.

Limitations of the study should be mentioned. As previously noted, the sample size does not permit to generalize the results of the study. Data on larger samples of cancer physicians are necessary to draw more precise conclusions about communication skills and its relationship with psychosocial orientation and burnout. Furthermore, even if the physicians were representative of the three hospitals where the research was carried out, they do not represent the whole population of cancer physicians in the three countries. A second limitation was that the specific academic curricula of the physicians coming from different countries and different backgrounds were not taken into account and this also prevents us to generalize the findings. Another limitation regards the fact that a series of other variables, which have been associated with communication skills, were not examined here. For example, Libert et al. (2003), have shown that doctors' locus of control influenced communication skills. Likewise, variables that have been shown to influence cancer physicians' burnout (e.g. intellectual stimulation, job satisfaction, organizational resources) and, consequently, communication skills (Ramirez et al., 1995, 1996), were not examined here. Last, evaluation of communications skills was based on self-reported instruments, which not necessarily represent the effective skills of the physicians in their daily clinical practice. As indicated by other authors (Fallowfield et al., 2003; Libert et al., 2003; Razavi et al., 2000), further studies should examine this area with more specific instruments (e.g. video/ audio-taped interviews).

In summary, physicians in the Southern European centers participating in this study reported low training in communication, although they tended to describe themselves as quite skilled in their relationships with cancer patients. Low psychosocial orientation and high level of burnout were associated with low confidence in communication skills and negative expected outcomes in communication. Training models to improve physicians' awareness of their problems in communication, their psychosocial orientation and their skills in managing difficult situations should be implemented in Southern Europe. 


\section{ACKNOWLEDGEMENTS}

The study, as part of a larger project ('Improving health staff's communication and assessment skills of psychosocial morbidity and quality of life in cancer patients: a study in Southern European countries'), has been funded by the European Community (Agreement SI2.307317 2000CVGG2-026-between the European Commission and the University of Ferrara). The research group wishes to thank all the colleagues participating in the study. We would also like to thank James Irby, PhD, who assisted in revising this paper and Cecilia Silva, $\mathrm{PhD}$, who assisted with the statistical analysis.

\section{REFERENCES}

Armstrong J, Holland J. 2004. Surviving the stresses of clinical oncology by improving communication. Oncology 18: 363-368.

Arora NK. 2003. Interacting with cancer patients: the significance of physicians' communication behavior. Soc Sci Med 57: 791-806.

Arraras JI, Illarramendi JJ, Valerdi JJ, James S. 1995. Truth-telling to the patient in advanced cancer: family information filtering and prospect for change. PsychoOncology 4: 191-196.

Ashworth CD, Williamson P, Montana D. 1984. A scale to measure physician beliefs about psychosocial aspects of patient care. Soc Sci Med 19: 1235-1238.

Back AL, Arnold RM, Tulsky JA, Baile WF, FryerEdwards KA. 2003. Teaching communication skills to medical oncology fellows. J Clin Oncol 21: 2433-2436.

Baile WF, Lenzi R, Kudelka AP et al. 1997. Improving physician-patient communication in cancer care: outcome of a workshop for oncologists. $J$ Cancer Educ 12: 166-173.

Baile WF, Kudelka AP, Beale EA et al. 1999. Communication skills training in oncology. Description and preliminary outcomes of workshops on breaking bad news and managing patient reactions to illness. Cancer 86: 887-897.

Catalan J, Burgess A, Pergami A, Hulme N, Gazzard B, Phillips R. 1996. The psychological impact on staff of caring for people with serious diseases: the case of HIV infection and oncology. J Psychosom Res 40: 425-435.

De Lorenzo F, Ballatori E, Di Costanzo F, Giacalone A, Ruggeri B, Tirelli U. 2004. Improving information to Italian cancer patients: results of a randomized study. Ann Oncol 15: 721-725.

Fallowfield L, Jenkins V. 1999. Effective communication skills are the key to good cancer care. Eur J Cancer 35: 1592-1597.

Fallowfield L, Jenkins V. 2004. Communicating sad, bad, and difficult news in medicine. Lancet 363: 312-319.
Fallowfield L, Lipkin M, Hall A. 1998. Teaching senior oncologists communication skills: results from phase I of a comprehensive longitudinal program in the United Kingdom. J Clin Oncology 16: 1961-1968.

Fallowfield L, Jenkins V, Farewell V, Solis-Trapala I. 2003. Enduring impact of communication skills training: results of a 12-month follow-up. $\mathrm{Br} J$ Cancer 89(8): 1445-1449.

Ferraz Gonçalves J, Castro S. 2001. Diagnosis disclosure in a Portuguese oncological centre. Palliat Med 15: $35-41$.

Gil F, Sirgo A, Méndez JI, Trigo JM et al. 2000. Inaccurate diagnosis information in patients with cancer: quality and associated factors. Rev Oncol 2: 33-36.

Grassi L, Magnani K. 2000. Psychiatric morbidity and burnout in the medical profession: an Italian study of general practitioners and hospital physicians. Psychother Psychosom 69: 329-334.

Grassi L, Giraldi T, Messina EG, Magnani K, Valle E, Cartei G. 2000. Physicians' attitudes and problems in truth-telling to cancer patients. Supp Care Cancer 8: $40-45$.

Grassi L, Travado L, Gil F, Sabato S, Rossi E, the SEPOS Group. 2004. Psychosocial morbidity and its correlates in cancer patients of the Mediterranean area: findings from the Southern European PsychoOncology Study. J Affect Dis 83: 243-248.

Grassi L, Travado L, Gil F, Campos R, Lluch P, Baile W. A communication intervention for training Southern European oncologists to recognize psychosocial morbidity in cancer patients. I-Development of the model and preliminary results on physicians' satisfaction. $J$ Cancer $E d u$, in press.

Grunfeld E, Whelan TJ, Zitzelsberger L, Willan AR, Montesanto B, Evans WK. 2000. Cancer care workers in Ontario: prevalence of burnout, job stress and job satisfaction. Can Med Assoc J 163: 166-169.

Jenkins V, Fallowfield L. 2002. Can communication skills training alter physicians' beliefs and behavior in clinics? J Clin Oncol 20(3): 765-769.

Kinnersley P, Stott N, Peters TJ et al. 1999. The patientcentredness of consultations and outcomes in primary care. Br J Gen Pract 49: 711-716.

Levinson W, Roter D. 1995. Physicians' psychosocial beliefs correlate with their patient communication skills. J Gen Intern Med 10: 375-379.

Libert Y, Janne P, Razavi D et al. 2003. Impact of medical specialists' locus of control on communication skills in oncological interviews. $\mathrm{Br} J$ Cancer $\mathbf{8 8}$ : 502-509.

Mager WM, Andrykowski MA. 2002. Communication in the cancer 'bad news' consultation: patient perceptions and psychological adjustment. Psycho-Oncology 11: $35-46$.

Maguire P. 1996. Assessing patients with cancer. The content, skill and process of assessment. 
Psychological Medicine Group, Cancer Research Campaign, Manchester.

Maguire P. 1999. Improving communication with cancer patients. Eur J Cancer 35(10): 1415-1422.

Maguire P, Pitceathly C. 2002. Key communication skills and how to acquire them. Br Med $J$ 325: 697-700.

Maguire P, Booth K, Elliott C, Jones B. 1996. Helping health professional involved in cancer care acquire key interwiewing skills - the impact of workshops. Eur J Cancer 32a: 1486-1489.

Maslach C, Jackson S. 1986. Maslach Burnout Inventory. Consulting Psychologist Press: Palo Alto, CA.

Mystadikou K, Liossi C, Vlachos L, Papadimitroiu J. 1996. Disclosure of diagnostic information to cancer patients in Greece. Palliat Med 10: 195-200.

Molina Siguero A, Garcia Perez MA, Alonso Gonzalez M, Cecilia Cermeno P. 2003. Prevalence of worker burnout and psychiatric illness in primary care physicians in a health care area in Madrid. Aten Primaria 3: 564-571.

Morasso G, Alberisio A, Capelli M, Rossi C, Baracco G, Costantini M. 1997. Illness awareness in cancer patients: a conceptual framework and a preliminary classification hypothesis. Psycho-Oncology 6: 212-217.

Parle M, Jones B, Maguire P. 1996. Maladaptive coping and affective disorders amongst cancer patients. Psychol Med 26: 735-744.

Parle M, Maguire P, Heaven C. 1997. The development of a training model to improve health professionals' skills, self-efficacy and outcome expectancies when communicating with cancer patients. Soc Sci Med 44(2): 231-240.

Pimentel FL, Ferreira JS, Vila Real M, Mesquita NF, Maia-Goncalves JP. 1999. Quantity and quality of information desired by Portuguese cancer patients. Supp Care Cancer 7: 407-412.

Ramirez AJ, Graham J, Richards MA et al. 1995. Burnout and psychiatric disorder among cancer clinicians. Br J Cancer 71: 1263-1269.
Ramirez AJ, Graham J, Richards MA, Cull A, Gregory WM. 1996. Mental health of hospital consultants: the effects of stress and satisfaction at work. Lancet 347: 724-728.

Razavi D, Delvaux N. 1997. Communication skills and psychological training in oncology. Eur J Cancer 33(Suppl 6): S15-S21.

Razavi D, Delvaux N, Marchal S, De Cock M, Farvacques C, Slachmuylder JL. 2000. Testing health care professionals' communication skills: the usefulness of highly emotional standardized role-playing sessions with simulators. Psycho-Oncology 9: 293-302.

Razavi D, Merckaert I, Marchal S et al. 2003. How to optimize physicians' communication skills in cancer care: results of a randomized study assessing the usefulness of posttraining consolidation workshops. $J$ Clin Oncol 21: 3141-3149.

Reis JC. 1998. O Sorriso de Hipócrates: a integração biopsicossocial dos processos de saúde e doença. (Hippocrates' smile: a biopsychosocial integration of health and disease processes). Vega: Lisboa, Portugal.

Roberts CS, Cox CE, Reintgen DS, Baile WF, Gibertini M. 1994. Influence of physician communication on newly diagnosed breast patients' psychologic adjustment and decision-making. Cancer 74(Suppl 1): 336-341.

Shilling V, Jenkins V, Fallowfield L. 2003. Factors affecting patient and clinician satisfaction with the clinical consultation: can communication skills training for clinicians improve satisfaction? Psycho-Onco$\log y$ 12: 599-611.

Stewart MA. 1984. What is a successful physicianpatient interview? A study of interactions and outcomes. Soc Sci Med 19: 167-175.

Stewart MA. 1996. Effective physician-patient communication and health outcomes: a review. Can Med Assoc J 152: 1423-1433.

Whippen DA, Canellos GP. 1991. Burnout syndrome in the practice of oncology: results of a random survey of 1,000 oncologists. J Clin Oncol 9: 1916-1920. 